\title{
Alcohol Advertising and Young People's Drinking
}

Barrie Gunter, Anders Hansen and Maria Touri

Published in Young Consumers, 2009, Volume 10, Number 1, pages 4-16. 


\begin{abstract}
Purpose - This paper aims to investigate relationships between reported alcohol consumption and exposure to alcohol advertising.

Design/methodology/approach - A survey of young people (17-21 years) was carried out in which they were questioned about their alcohol consumption habits, types of alcohol they consume, exposure to alcohol advertising, and a range of other factors linked to drinking (e.g., parental and peer groups alcohol-related behaviour and attitudes). General alcohol consumption was measured within three time-frames: own lifetime, past year and past month.

Findings - The results showed no significant relationships between exposure to any type of alcohol advertising (cinema, magazine, TV) and general alcohol consumption. Exposure to televised advertising for alcopops and for cider in each case emerged as a significant predictor of consumption of each of those types of alcohol. While there was no evidence that alcohol advertising plays a significant role in shaping general alcohol consumption among young people, it does seem to play a part in driving consumption of certain types of alcoholic beverage.

Research limitations/implications - Self-completion questionnaires were used and the sample was based in central east England.

Practical implications - The results can inform current debates about the role of advertising in young people's drinking.

Originality/value - A wider range of alcohol-related consumption and alcohol advertising exposure behaviours was examined in this study than in most other published surveys that have investigated relationships between these classes of variables.
\end{abstract}

Keywords: Alcoholic drinks, Advertising, Young adults

Paper type: Research paper 


\section{Introduction}

There is growing concern about alcohol consumption among young people. Alcohol abuse and dependence have been recognised as significant health issues for many years. Irresponsible and excessive consumption can produce damaging health consequences at great cost to the individual, their family and society (Ford, Hawkes \& Elliott, 2008).

The growth of excessive alcohol consumption, where drinking large quantities becomes an end in itself, is a worrying trend. This type of alcohol consumption is often associated with outbreaks of antisocial behaviour among young people and can have serious and damaging health consequences for those who allow their drinking to excess to continue over extended periods of time (Wyllie, Millard \& Zhang, 1996; Richardson \& Budd, 2003; Matthews, Shepherd \& Sivarajasingham, 2006). Although drunkenness occurs across all age groups, it is most commonplace among young people in their mid to late teens (Alcohol Concern, 2003).

How to tackle this social problem has posed a major challenge to government. Empirical research has identified a range of potential influences on the onset of youth drinking including parents and peer groups (Adlaf \& Kohn, 1989; Houghton \& Roche, 2001; Smart, 1988). Other evidence identified alcohol advertising as an important factor. There is certainly empirical evidence in support of the alleged influences of alcohol advertising (Aitken, Eadie, Leathar, McNeill, \& Scott 1988; Aitken, 1989; Young, 2003). Exposure to televised advertising could raise brand awareness and the latter in turn was linked to future drinking (Lipsitz, Brake, Vincent \& Winters, 1993).

Children themselves have been found to believe that alcohol advertising can cause alcohol consumption (Lieberman \& Orlandi, 1987; Wyllie et al., 1989, 1998). Through raising young people's awareness and familiarity with alcohol, advertising is a contributor towards their decision eventually to take up drinking (Hastings, Anderson, Cooke \& Gordon, 2005). Liking of alcohol advertisements has been significantly linked to drinking alcohol among young adults in multi-variate statistical tests that took into account other potential causal factors such as parent and peer variables (Wyllie et al., 1998). 
Evidence that has linked alcohol consumption among young directly to advertising exposure has derived from surveys (Atkin, Neuendorf \& McDermott, 1983; Connolly, Casswell, Zhang \& Silva, 1994; Robinson, Chen \& Killen, 1998; Wyllie, Zhang \& Casswell, 1998) and experiments (e.g., McCarty \& Ewing, 1983; Kohn \& Smart, 1984; Sobell et al., 1986; Lipsitz, Brake, Vincent and Winters, 1993). Surveys can be further divided into those that have obtained data from respondents at one point in time (e.g., Unger, Schuster, Zogg, Dent \& Stacy, 2003) versus those that have obtained data from the same respondents on more than one occasion (e.g., Stacey, Zogg, Unger \& Dent, 2004; Ellickson, et al., 2005).

Most of the research that has attempted to demonstrate relationships between alcohol advertising exposure and consumption has been conducted in the 'field' among large samples of young people and has been dependent upon their self-reports about their behaviour. Such studies use survey methodology to determine whether reported exposure to alcohol advertising is correlated with or predictive of alcohol consumption.

Some experimental studies conducted in laboratory conditions have indicated that showing televised alcohol advertisements to individuals can raise their short-term interest in alcohol consumption as tested virtually immediately after advertising exposure, when alcohol is made available, compared to matched individuals who were not exposed to any alcohol advertising (e.g., Kohn \& Smart, 1984). Others failed to reproduce similar findings (e.g., Kohn \& Smart, 1987; Sobell et al., 1986). None of these investigations revealed anything about the role advertising might play in the genesis of alcohol consumption in individuals. Exposure to televised alcohol advertising has also been found to produce a decrease in the confidence of heavy drinkers that they could resist drinking heavily again in the future (Sobell, Sobell, Toneatto, \& Leo, 1993).

Some cross-sectional surveys have reported significant statistical associations between reported alcohol advertising exposure and alcohol consumption (Atkin \& Block, 1984; Atkin, Neuendorf \& McDermott, 1983; Robinson et al., 1998) or between liking of alcohol adverts and alcohol consumption (Wyllie et al., 1998). Longitudinal surveys have also indicated links between self-reports of advertising exposure and alcohol consumption among young people (Connolly et al., 1994; Ellickson et al., 2005). 
Longitudinal survey research conducted in New Zealand reported that the more male teenagers were able to recall beer advertisements at the age of 15 years, the more they drank at 18 years. This finding occurred only for beer drinking and not for consumption of wine or spirits. The advertising recall effect only had a modest effect even in the case of beer drinking (Connolly, Casswell, Zhang \& Silva, 1994). This finding was reinforced in further longitudinal research that followed through 18 year olds until the age of 21 years which found that earlier liking of televised alcohol advertisements and associated brand allegiance were associated with greater volume of beer consumption later on (Casswell \& Zhang, 1998). The reasons why beer advertising proved to be most potent in this research is not fully explained. There may have been differences in the extent to which beer advertising campaigns were run in the major mass media as compared to campaigns for other alcohol products. There may have been differences in production treatments that rendered beer advertisements more attentiongrabbing. Focus group interviews with children and teenagers have indicated that they often display liking of beer advertisements (Nash, 2002). Of course, liking of alcohol advertisements or even associations between liking and reported liking or consumption of alcohol products even in large-scale surveys do not demonstrate causal relationships between advertising and consumption (Young, 2003).

Research among Californian teenagers indicated that liking of advertisements, brand recall and receptivity to alcohol marketing predicted alcohol use. The findings suggested that exposure to alcohol advertising could produce favourable opinions about alcohol among young people and that this may in turn increase their likelihood of future consumption (Unger, Schuster, Zogg, Dent \& Stacy, 2003). A further US study of 13 to 14 year-olds found that increased exposure to alcohol advertisements on television in the first year of the study was associated with greater likelihood of consuming beer or wine a year later (Stacy, Zogg, Unger \& Dent, 2004).

Research conducted over time among over 3,000 American youth aged 12 to 15 years in which they were asked questions designed to track their alcohol consumption behaviour, exposure to different kinds of alcohol advertising and other social factors linked to drinking. Research with US 13 to 15 year-olds who were questioned three times over three years reported that for drinkers and non-drinkers in year 1, greater exposure to 
alcohol advertising in year 2 made it more likely that teenagers would drink alcohol in year 3 (Ellickson, et al., 2005).

This paper reports a new survey-based study of antecedents of alcohol drinking behaviour among young people in central-east England. Data were obtained about alcohol consumption, exposure to alcohol advertising and family and peer group drinking habits and attitudes towards alcohol. A wider range of alcohol-related consumption and alcohol advertising exposure behaviours was examined in this study than in most other published surveys that have investigated relationships between these classes of variables. Although, this research cannot demonstrate cause-effect relationships in any direct sense, it does attempt to show the strength of associative links specifically between reported exposure to alcohol advertising in different media and reported alcohol consumption, in the presence of simultaneous statistical controls for other social factors, such as parental and peer group influences.

In addition to measuring self-reports of overall alcohol consumption and advertising exposure, respondents were questioned about their consumption of specific categories of alcoholic beverage (beers, cider, designer drinks, spirits, wines) and exposure to advertising for brands representing each of those beverage types. In view of the conflicting evidence from earlier research, a number of research questions were constructed rather than hypotheses about relationships between reported exposure to alcohol advertising and alcohol consumption.

RQ1. Is greater reported exposure to alcohol advertising significantly related to reported frequency of alcohol consumption? There is previous evidence that affirms this link (e.g., Lipsitz, Brake, Vincent \& Winters, 1993; Stacey, et al., 2004) and disconfirms it (e.g., Strickland, 1981, 1982, 1983).

RQ2. Does reported exposure to alcohol advertising predict frequency of alcohol consumption in the presence of controls for family and peer group variables? Research among teenagers in the United States has indicated that early exposure to alcohol advertising predicted likelihood of alcohol consumption one or two years later, even when social factors such as parental and peer group drinking were statistically controlled (Ellickson et al., 2005). Research with college students, however, found no evidence that 
exposure to televised advertising for alcohol produced increased interest in drinking beer immediately afterwards (Sobell et al., 1986).

RQ3. Are certain forms of media advertising of alcohol more powerfully related to alcohol consumption than others? Most studies of the impact of alcohol advertising have focused on television advertising. One study, however, found that magazine advertising and point-of-sale advertising displayed stronger relationships with alcohol consumption propensity a year or two later than did other forms of advertising (Ellickson, et al., 2005).

RQ4. Is consumption of some types of alcoholic beverage more significantly related to alcohol advertising exposure than others? Not all alcohol advertising impact studies have differentiated between different types of alcoholic drink, but in those that have, differences have emerged between types of product in terms of strength of relationships between reported advertising exposure and alcohol consumption. Hence, beer and wine consumption were found to be greater among US teenagers who reported greater advertising exposure for these products, while this result did not emerge for other types of alcoholic drink (Stacey et al., 2004).

RQ5. Is alcohol consumption predicted similarly or differently by alcohol advertising exposure among males and females? Both young women and young men have been found to display greater interest in drinking alcohol after exposure to alcohol advertising under controlled exposure conditions (Kohn \& Smart, 1984; 1987). It is unclear, however, whether such effects are anything more than short-term and that they wear off soon after advertising exposure has taken place. Given continued concern about the prevalence of alcohol consumption, including excessive consumption, among young women (Gill, Donaghy, Guise \& Warner, 2007; MacRae, 2007), it is important to separate the genders in examining relationships between alcohol consumption and reported exposure to alcohol advertising.

\section{Methodology}

A self-completion questionnaire survey was conducted with young people aged 17 to 21 years. Respondents were recruited from among university and further education college populations in Leicester, UK. Respondents were volunteers accessed via class tutors. 
Most questionnaires were completed at the end of class sessions, while some were returned by respondents in their own time to an address provided. A researcher explained to respondents the purpose of the survey and gave clear assurances that all questionnaires would be completed anonymously. Data could not therefore be traced back to specific respondents. In consequence, respondents were invited to be as honest as possible in giving their answers.

\section{Sample details}

The total sample of 298 respondents comprised 169 university students and 129 secondary school students of whom $60 \%$ were female and $40 \%$ were male. The age range was 17 to 23 years, with the following age breakdown: 17 years (10\%), 18 years (29\%), 19 years (34\%), 20 years (15\%) and 21+ years (12\%). The sample comprised mainly white British students (41\%). The second most prevalent ethnic group comprised students of Indian descent (28\%), Black African (6\%), Pakistani/Bangladeshi (6\%), Other Asian (6\%), Other white (6\%), other (7\%).

\section{The Questionnaire}

Young people's alcohol consumption was measured via a self-completion questionnaire survey which explored three principal areas: respondents' own consumption of alcoholic beverages; reports of the alcohol consumption habits of people known to them; and reported exposure to advertising for alcoholic drinks.

The measure of general consumption of alcohol comprised a self-report of how many occasions they had had any alcoholic beverages to drink 'during past 30 days'. Responses were given to a seven-point scale ranging from 'never' to ' $40+$ times'.

In relation to different types of alcoholic drink, respondents were presented with a list of alcohol brand names, covering beers, coders, spirits, wines and alcopops, and were asked to indicate in each case how often they had drunk it. A four-point scale was provided: 'never', 'once or twice', 'a few times', 'a lot'. Scores were aggregated across listed brands in each drinks category to produce a single consumption score for each type of alcoholic drink. 
A further section of the questionnaire contained questions about media consumption and reported exposure to alcohol advertising. Respondents were asked to estimate the number of hours per week they watched television, which TV channels or services they could receive and how often they watched TV after 9pm. Another question probed frequencies of watching a number of different TV channels. Respondents were also asked how often in the past six months they had been to the cinema. Finally, respondents were given a list of alcohol brands and asked them how often in the past six months they had seen advertising for any of these brands on television, at the cinema or in magazines. A four-point frequency scale was used throughout: 'never', 'once or twice', '3-6 times' and '7+ times'. The latter frequency scale was adopted to provide a standardized that could be applied to all three media. Given that cinema attendance was expected to be relatively infrequent compared to television viewing, this measure was deemed appropriate for reported exposure to advertising in a cinema context. Pilot tests had indicated that respondents similar to those used in the main survey expressed no difficulty with this question. Nevertheless, it must be seen as providing a very general indication of alcohol brand advertising exposure.

A further set of questions explored with respondents the presence in their lives of other people who drank alcohol. Initial questions asked respondents to indicate the frequency with which their father/male guardian, mother/female guardian and best friend drink alcohol ('not at all', 'only very occasionally', 'every week', 'every day', 'don't know', 'do not have father/mother/guardian/best friend').

Respondents were then asked how often ('never', 'once or twice', 'a few times', 'many times') their parents/guardians had given them alcohol to drink at home. The same response scale was then used by respondents to estimate how often they had seen their parents/guardian drunk after having had too much alcohol to drink.

The social side of drinking was explored through questions that asked respondents how often they met with friends in bars or clubs where alcohol is served, how many of their friends drink alcohol, and how many of their friends get drunk at least once a week. They were also asked whether their parents or guardians know where they spend their Saturday nights and what parents reaction would be if they got drunk ('would not allow it', 'would discourage it', 'would not mind', 'would approve of it'). 
Personal details were also collected from respondents that included their gender, age, religion and ethnic group.

\section{Results}

Descriptive statistics about alcohol consumption are presented initially followed by the results of series of analyses designed to identify predictors of frequency of alcohol consumption and consumption of different types of alcohol.

\section{Consumption of Alcohol Drinks}

In the past month, one in three (34\%) said they had drunk no alcohol, while $16 \%$ said they had drunk 10 to 19 times in the last one month and only $8 \%$ said they had had alcohol 40+ times.

Again, during the month leading up to the survey, $60 \%$ of respondents had reportedly consumed spirits, $46 \%$ spirits, $37 \%$ beer, $35 \%$ alcopops, and $21 \%$ cider. Females were more likely than males to have reportedly drunk spirits (57\% versus 39\%), wine (56\% versus 35\%), and alcopop (40\% versus 31\%). Males were more likely thane females to have drunk beer (40\% versus $35 \%$ ) and cider (29\% versus $17 \%$ ).

\section{Predictors of Alcohol Consumption}

In order to identify potential factors that determine the drinking profile of respondents a series of multiple regression analyses was conducted over data from the total sample. In addition, two further series of multiple regression analysis were conducted among male and female respondents. These analyses were computed in relation to [1] general alcohol consumption and [2] consumption of beers, cider, spirits, wine and alcopops.

\section{[1] General Alcohol Consumption}

Analyses of the overall alcohol consumption among respondents in the past month was the key dependent variable measured on a seven-point scale $(1=$ 'never' and $7=40+$ times). Predictor variables comprised demographic variables (gender and age); familyrelated variables (reported consumption of alcohol by father/male guardian, mother/female guardian, whether respondents were given alcohol by their parents, frequency of seeing parents drunk, parents knowing respondent's whereabouts on 
Saturday nights, parents' likely reaction to respondent getting drunk); peer group variables (amount of alcohol consumption by best friend, number of friends who drink, frequency of meeting friends in places where alcohol is served); media consumption variables (amount of TV viewing, TV viewing after 9pm); and alcohol advertising exposure (on TV, at cinema and in magazines). All predictor variables were entered together.

For reported alcohol consumption over the 'last month', 64\% of the variance was accounted for by the predictor variables (Adjusted Multiple R Square $=0.64$ ), $68 \%$ of the variance was accounted for by the predictor variables for the male respondents only (Adjusted Multiple R Square $=0.68$ ) and 62\% for the female respondents (Adjusted Multiple R Square = 0.62).

Table 1: Predictors of Alcohol Consumption in Last Month

\begin{tabular}{|c|c|c|c|}
\hline Predictors & Beta & $\mathbf{T}$ & $\mathbf{P}<$ \\
\hline Gender & -.009 & -.23 & .82 \\
\hline Age & .011 & .28 & .78 \\
\hline Father/male guardian alcohol consumption & .001 & .02 & .98 \\
\hline Mother/ female guardian alcohol consumption & .023 & .42 & .68 \\
\hline Best friend alcohol consumption & .059 & 1.25 & .21 \\
\hline Alcohol given by parents/guardians at home & .307 & 4.72 & .000 \\
\hline Seeing parents/guardians drunk & .031 & .62 & .54 \\
\hline Meeting friends where alcohol is served & .376 & 6.05 & .000 \\
\hline Number of friends who drink alcohol & -.025 & -.39 & .70 \\
\hline Number of friends getting drunk once a week & .133 & 2.38 & .02 \\
\hline $\begin{array}{l}\text { Parents/ guardians knowing where Saturdays } \\
\text { nights are spent }\end{array}$ & .014 & .34 & .74 \\
\hline $\begin{array}{l}\text { Parents'/ Guardians' anticipated reaction to } \\
\text { getting drunk }\end{array}$ & .038 & .92 & .36 \\
\hline Amount of TV watching & .027 & .56 & .58 \\
\hline TV watching after $9 \mathrm{pm}$ & -.014 & -.29 & .77 \\
\hline Alcohol advertising on TV & .026 & .57 & .57 \\
\hline Alcohol advertising at the cinema & .048 & 1.16 & .25 \\
\hline Alcohol advertising in magazines & .022 & .49 & .63 \\
\hline
\end{tabular}

Respondents' alcohol consumption was predicted by the increased frequency of being given alcohol by their parents, as well as by the greater number of friends who would reportedly get drunk once a week (see Table 1). Separate analyses among males and females showed that having a greater number of friends who reportedly get drunk 
each week was a significant predictor among male respondents only (Beta, 0.27, $\mathrm{t}=2.74$, $\mathrm{p}<0.007)$.

\section{[2] Type of Alcohol Consumption}

A further series of multiple regression analyses was run to reveal predictors of the frequency of the consumption of a number of distinct alcoholic beverage types. The criterion for the selection of the brands included in the questionnaire was the volume of TV, cinema and print advertising for each brand in the UK from 2004 to 2006. The frequency of reported consumption of each advertised brand was measured with a fourpoint scale ranging from 'never' and to 'a lot'. The predictor variables were the same as those used in the excessive alcohol consumption analyses.

\section{Predictors of Beer and Alcopop Drinking}

In the consumption of advertised brands for the various types of alcohol, it emerged that the most statistically significant multiple regression analyses were for the consumption of beer and alcopops $(\mathrm{F}(32,264)=23.37, \mathrm{p}<0.001$ and $\mathrm{F}(32,324)=22.3, \mathrm{p}<0.001$ respectively). The overall percentages of variance accounted for by the predictor variables were $73 \%$ for both beer and alcopop brands (Adjusted Multiple R Square = 0.73). However, although the consumption of alcopop produced a statistically significant regression analysis for the two genders separately as well (Adjusted Multiple R Square = 0.75 for the male respondents and Adjusted Multiple R Square $=0.70$ for the female respondents), the respective analysis for the consumption of beer proved considerably more significant for the males (Adjusted Multiple $\mathrm{R}$ Square $=0.82$ for the male respondents and Adjusted Multiple R Square $=0.57$ for the female respondents).

It emerged that the heavier consumption of beer and alcopop advertised brands was predicted by the increased frequency of buying alcohol when visiting a store. In the case of beer brands, heavier reported consumption was also predicted by the more frequent purchase of alcohol from a store during the 'last month'. Moreover, in both cases, the heavier consumption was significantly related to the greater number of alcoholic drinks respondents said they need to consume to get drunk. For the heavier overall consumption of the beer brands, the most significant predictor was the greater consumption of beer in 
the 'last 30 days', together with the lighter consumption of spirits, alcopops and cider in the 'last 30 days'. Another predictor of overall beer drinking was the older the age at which respondents had cider for the first time. The younger age at which respondents reportedly got drunk for the first time was also predicted by greater consumption of beer brands (Table 2).

Table 2: Predictors of Consumption of Most Advertised Beer Brands in 2004-2006

\begin{tabular}{|c|c|c|c|}
\hline Predictors & Beta & $\mathbf{T}$ & $\mathbf{p}<$ \\
\hline Gender & -.070 & -1.71 & .090 \\
\hline Age & .028 & .80 & .43 \\
\hline Alcohol purchase when visiting a store & .226 & 3.19 & .002 \\
\hline Drank beer for the first time & .006 & .13 & .90 \\
\hline Drank cider for the first time & .128 & 2.82 & .005 \\
\hline Drank wine for the first time & .010 & .20 & .84 \\
\hline Drank spirits for the first time & .018 & .29 & .77 \\
\hline Drank alcopop for the first time & .004 & .08 & .94 \\
\hline Got drunk for the first time & -.174 & -2.77 & .006 \\
\hline Beer consumption/ Last 30 days & .631 & 11.25 & .000 \\
\hline Cider consumption/ Last 30 days & -.155 & -3.20 & .002 \\
\hline Wine consumption/ Last 30 days & .020 & .41 & .68 \\
\hline Spirits consumption/ Last 30 days & -.194 & -3.004 & .003 \\
\hline Alcopop consumption/ Last 30 days & -.106 & -2.55 & .01 \\
\hline Alcohol purchase /last 30 days & .123 & 2.52 & .01 \\
\hline Five or more drinks in a row/last 30 days & .017 & .24 & .81 \\
\hline Number of drinks needed to get drunk & .172 & 2.71 & .007 \\
\hline Father/male guardian alcohol consumption & .030 & .66 & .51 \\
\hline Mother/Female guardian alcohol consumption & .048 & .97 & .34 \\
\hline Best friend alcohol consumption & -.008 & -.18 & .85 \\
\hline Given alcohol by parents/guardians & .089 & 1.43 & .16 \\
\hline Seen parents/guardians drunk & -.030 & -.65 & .52 \\
\hline Meet friends where alcohol is served & .093 & 1.49 & .14 \\
\hline Number of friends who drink alcohol & .005 & .08 & .94 \\
\hline Number of friends who get drunk once a week & -.091 & -1.68 & .10 \\
\hline $\begin{array}{l}\text { Parents/ guardians knowing where Saturdays } \\
\text { nights are spent }\end{array}$ & -.047 & -1.29 & .20 \\
\hline $\begin{array}{l}\text { Parents'/ Guardians' anticipated reaction to } \\
\text { getting drunk }\end{array}$ & .054 & 1.45 & .15 \\
\hline TV watching & .004 & .10 & .92 \\
\hline TV watching after $9 \mathrm{pm}$ & -.002 & -.04 & .97 \\
\hline Beer advertising on TV & .014 & .36 & .72 \\
\hline Beer advertising at the Cinema & .020 & .57 & .57 \\
\hline Beer advertising in Magazines & .000 & .008 & .99 \\
\hline
\end{tabular}


Interestingly, the heavier overall consumption of the advertised alcopop brands was predicted by the older the age at which respondents tried alcopop for the first time and by the heavier reported consumption of alcopop over the 'last 30 days'. It appears that students who prefer alcopop are less likely to drink beer as the increased frequency of consuming alcopop brands was also predicted by the lighter consumption of beer in the 'last 30 days'. A greater likelihood to binge drink was an additional predictor of heavier consumption of the advertised alcopop brands.

These three predictors proved significant in the separate gender analyses for both male and female respondents. In addition, female respondents who preferred alcopops were less likely to drink beer as the increased frequency of consuming alcopop brands was also predicted by the lighter consumption of beer in the 'last 30 days' (Beta, $-0.095, \mathrm{t}$ $=-1.50, \mathrm{p}<0.1)$. Female respondents who reported a preference for alcopop brands were more likely to need more drinks to get drunk (Beta, 0.22, $\mathrm{t}=2.54, \mathrm{p}<0.01$ ), while they also watched more TV after 9pm (Beta, 0.16, $\mathrm{t}=2.12, \mathrm{p}<0.04)$.

Alcopop was one of the two types of beverage, along with cider, the heavier consumption of which was predicted by the increased frequency of seeing advertisements of the same type on television. However, it emerged that the specific predictor variable was significant only among the male respondents (Beta, 0.21, t =3.05, $\mathrm{p}<0.003$ ). Another significant predictor for the consumption of alcopop brands that re-emerged in the gender analysis, but only for the male group, was the increased frequency of buying alcohol when visiting a store (Beta, 0.4, $\mathrm{t}=3.25, \mathrm{p}<0.002)$ (Table 3 ). 
Table 3: Predictors of Consumption of Most Advertised Alcopop Brands in 20042006

\begin{tabular}{|c|c|c|c|}
\hline Predictors & Beta & $\mathbf{t}$ & $\mathbf{p}<$ \\
\hline Gender & .060 & 1.48 & .14 \\
\hline Age & -.071 & -1.95 & .05 \\
\hline Alcohol purchase when visiting a store & .264 & 3.74 & .000 \\
\hline Drank beer for the first time & -.079 & -1.57 & .12 \\
\hline Drank cider for the first time & .009 & .19 & .85 \\
\hline Drank wine for the first time & -.015 & -.29 & .78 \\
\hline Drank spirits for the first time & .024 & .386 & .70 \\
\hline Drank alcopop for the first time & .137 & 2.71 & .007 \\
\hline Got drunk for the first time & .061 & .10 & .32 \\
\hline Beer consumption/ Last 30 days & -.121 & -2.22 & .03 \\
\hline Cider consumption/ Last 30 days & -.042 & -.87 & .39 \\
\hline Wine consumption/ Last 30 days & -.027 & -.55 & .58 \\
\hline Spirits consumption/ Last 30 days & -.077 & -1.18 & .24 \\
\hline Alcopop consumption/ Last 30 days & .197 & 4.67 & .000 \\
\hline Alcohol purchase /last 30 days & .050 & .10 & .32 \\
\hline Five or more drinks in a row/last 30 days & .168 & 2.42 & .02 \\
\hline Number of drinks needed to get drunk & .191 & 2.99 & .003 \\
\hline Father/male guardian alcohol consumption & .029 & .63 & .53 \\
\hline Mother/Female guardian alcohol consumption & -.009 & -.17 & .86 \\
\hline Best friend alcohol consumption & .009 & .20 & .84 \\
\hline Given alcohol by parents/guardians & .089 & 1.41 & .16 \\
\hline Seen parents/guardians drunk & .017 & .38 & .71 \\
\hline Meet friends where alcohol is served & .000 & .008 & .99 \\
\hline Number of friends who drink alcohol & .120 & 1.94 & .05 \\
\hline Number of friends who get drunk once a week & -.026 & -.47 & .64 \\
\hline $\begin{array}{l}\text { Parents/ guardians knowing where Saturdays } \\
\text { nights are spent }\end{array}$ & -.032 & -.85 & .40 \\
\hline $\begin{array}{l}\text { Parents'/ Guardians' anticipated reaction to } \\
\text { getting drunk }\end{array}$ & .033 & .89 & .38 \\
\hline TV watching & -.010 & -.22 & .83 \\
\hline TV watching after 9pm & .115 & 2.55 & .02 \\
\hline Alcopop advertising on TV & .095 & 2.29 & .02 \\
\hline Alcopop advertising at the Cinema & -.006 & -.17 & .87 \\
\hline Alcopop advertising in Magazines & -.035 & -.83 & .41 \\
\hline
\end{tabular}

\section{Predictors of Spirits Drinking}

The multiple regression analysis for the consumption of advertised spirits brands was significant $(\mathrm{F}(32,266)=19.7, \mathrm{p}<0.001)$ with $69 \%$ of the overall variance accounted for by the predictor variables (Adjusted Multiple R Square $=0.69$ ). In the separate gender analysis, the predictor variables accounted for $77 \%$ of the variance in this variable in the male sample well (Adjusted Multiple R Square $=0.77$ ) and for $60 \%$ of the variance for 
the female sample (Adjusted Multiple R Square $=0.60$ ), revealing another significant discrepancy between the two genders.

Similar to beer and alcopop brands, the heavier consumption of spirits was predicted by the more frequent purchase of alcohol when visiting a store generally and in the 'last month' (Beta $=0.21, \mathrm{t}=2.73, \mathrm{p}<0.007)$. However, the purchase of alcohol when visiting a store was a significant predictor only for the heavier consumption of spirits brands by male respondents, as the regression analysis computed for the two genders demonstrated (Beta, 0.49, $\mathrm{t}=4.00, \mathrm{p}<0.001$ ). This predictor did not emerge among female respondents.

Respondents who reportedly consumed more spirits brands were also those saying they needed more alcoholic drinks to get drunk $($ Beta $=0.28, \mathrm{t}=4.02, \mathrm{p}<0.001)$. This finding could be explained by the fact that, as noted earlier, respondents who had consumed spirits the last time they drank alcohol, consumed them in smaller quantities than other beverage types. The heavier consumption of wine in the last month was another predictor of the more frequent consumption of spirits brands $($ Beta $=0.13, t=$ $2.51, \mathrm{p}<0.01)$. Although the specific predictor re-emerged in the analysis conducted for both the male and female respondents, it was found to be more significant among the male respondents $($ Beta, 1.0, $\mathrm{t}=2.64, \mathrm{p}<0.01)$ than for the female respondents $($ Beta $=$ $0.10, \mathrm{t}=1.27, \mathrm{p}<0.02)$.

\section{Predictors of Cider Drinking}

A somewhat weaker multiple regression analysis emerged for the consumption of cider $(\mathrm{F}(32,267)=12.4, \mathrm{p}<0.001)$ where the selected predictor variables explained $60 \%$ of the variance in the specific variable (Adjusted Multiple $\mathrm{R}$ Square $=0.60$ ). A similar finding was also reflected in the gender analysis with the selected predictor variables explaining $63 \%$ of the variance in the male group (Adjusted Multiple R Square $=0.63$ ) and only $50 \%$ in the female group (Adjusted Multiple R Square $=50$ ). Cider was the second type of beverage the heavier consumption of which was predicted by the increasing exposure to TV advertising, but the connection of the two variables was significant only for the female respondents (Beta, 0.27, $t=3.75, p<0.000$ ). However, 
because only one cider brand - Strongbow - was featured in the analysis, the findings should be treated with caution.

\section{Predictors of Wine Drinking}

The regression analysis for the consumption of the most advertised brands of wine was statistically the weakest among the five types of beverage $(F(32,267)=3.63)$. In this case, the predictor variables accounted for only $24 \%$ of the variance in this variable. A much weaker regression analysis emerged in the analysis conducted for the two genders as well. Hence, the predictor variables accounted for only $33 \% \%$ of the variance in the male group and $10 \%$ in the female group.

The heavier consumption of the most advertised wine brands was mostly predicted by the younger age at which respondents reportedly first got drunk (Beta $=-0.20, \mathrm{t}=-$ $2.02, \mathrm{p}$ 0.04), the more drinks they said they needed to consume to get drunk (Beta $=$ $0.37, \mathrm{t}=3.48, \mathrm{p}<0.001)$, the more frequent purchase of any alcoholic beverages during the 'last month' (Beta $=0.25, \mathrm{t}=3.00, \mathrm{p}<0.003$ ), and the more their father/male guardian drank $($ Beta $=0.16, \mathrm{t}=2.09, \mathrm{p}<0.02)$. Parental influence was evident in the consumption of wine specifically among the female respondents with the heavier reported consumption by the father or male guardian being another predictor for this variable (Beta, 0.23, $\mathrm{t}=2.12, \mathrm{p}<0.04)$. 


\section{Discussion}

A survey was reported of young people's alcohol consumption that examined the significance of alcohol advertising exposure, alongside family and peer group factors, as predictors of reported consumption. Consumption was measured here in terms of selfreported frequencies of drinking alcohol in general and consumption of different types of alcoholic beverage (beer, cider, wine, spirits and alcopops). Five research questions were addressed by this investigation.

RQ1 asked if greater reported exposure to alcohol advertising was significant related to reported frequency or amount of alcohol consumption. Following on from this RQ2 asked whether reported exposure to alcohol advertising predicted alcohol consumption in the presence of controls for family and peer group factors. Previous research had indicated that exposure to alcohol advertising is associated with young persons' consumption of alcohol (Atkin \& Block, 1984; Ellickson et al., 2005).

In relation to the overall amount of reported drinking of alcohol, there was no evidence here that exposure to alcohol advertising was an important predictor variable. Instead, parental and peer group influences emerged as more significant. Parental drinking (especially by the male parent or guardian) and having friends who drink and spending time drinking with friends were the most important factors that underpinned how often the young people in this sample reported consumption of alcohol. This pattern was true regardless of whether they were asked about how often they drank during their lifetime, over the previous 12 months or over the previous 30 days.

RQ3 asked whether the potency of alcohol advertising to influence alcohol consumption varied between media. Researchers have previously reported that young people often display a strong liking for alcohol advertising, and especially that which appears on television (Aitken et al., 1988; Wyllie et al., 1998). Data produced here indicated that there are differences in the potential effects of advertising between cinema, magazine and television advertising but that these occurred in relation to reported consumption of specific types of alcoholic beverage rather than in relation to overall reported consumption of alcohol. Only TV advertising emerged as a significant predictor and then only in relation to reported consumption of cider and alcopops. 
RQ4 asked whether alcohol advertising effects varied between different types of alcoholic beverage. Previous research found that reported exposure to television alcohol advertising was significantly related to teenagers' reported consumption of beer and wine (Stacy et al., 2004). Elsewhere, a modest effect of alcohol advertising recall was fond in relation to beer drinking among teenagers (Connolly et al., 1994). To address this question, a series of analyses examined predictors of reported consumption of five different types of alcohol (beer, cider, wine, spirits and alcopop), based on respondents' reported consumption of the most advertised brands (per beverage type) during 20042006. At the outset all these types of alcoholic beverage were aggregated to produce an overall measure of alcohol consumption. The extent to which specific types of alcoholic beverage - especially beer, cider and spirits - had been recently consumed was, not surprisingly, the major predictor of this measure of general alcohol consumption. None of the advertising measures predicted overall alcohol consumption, but there was a point-ofsale factor. Respondents who said that they regularly purchased alcohol when visiting a shop were more regular consumers of the mot advertised alcohol brands.

As noted above, reported consumption of only two types of alcoholic beverage cider and alcopop - was predicted by exposure to any form of alcohol advertising. There were no significant advertising predictors of reported consumption of the most advertised brands of beer, wine or spirits. In the case of coder and alcopop drinks, exposure to televised advertising of these drinks predicted frequency of consumption of their most advertised brands. In addition, reported frequencies of consumption of the most advertised brands of cider and alcopop and also of spirits were also predicted by a pointof-sale influence (regularity of make alcohol purchases when visiting a shop).

RQ5 asked whether there were any differences in relationships between reported alcohol consumption and advertising exposure between male and female respondents. Boys have previously been found to exhibit stronger dependence than girls on advertising for information about alcohol (Wyllie et al., 1998). A series of separate multiple regression analyses for each gender addressed this question. A gender difference emerged in the case of alcopops where for male respondents only, reported exposure to televised advertising for these drinks predicted their consumption. 
This research has indicated therefore that a range of factors in a young person's environment are linked to their consumption of alcohol. Alcohol advertising on television (though not in any other media) and point-of-sale attention to alcohol are among the key predictors. What this research has also shown, however, is that in identifying possible influences of alcohol advertising, it is important to differentiate between different types of alcohol consumption. It is not alcohol consumption per se that is affected by advertising, but specific types of alcohol consumption.

\section{References}

Adlaf, E. M., \& Kohn, P. M. (1989) Alcohol advertising, consumption and abuse: A covariance structural modelling look at Strickland's data. British Journal of Addiction, 84(7), 749-757.

Aitken, P. (1989) Television alcohol commercials and under-age drinking. International Journal of Advertising, 8, 133-150.

Aitken, P.P., Eadie, D. R., Leathar, D. S., McNeill, R. E., \& Scott, A. C. (1988) Television advertisements for alcoholic drinks do reinforce under-age drinking. British Journal of Addiction, 83, 1399-1419.

Alcohol Concern (2003, January) Teenage Drinkers - A follow-up study of alcohol use among 15-17 year olds in England. London, UK: Alcohol Concern.

Atkin, C., \& Block, N. (1984) The effects of alcohol advertising. In T. C. Kinnear (Ed). Advances in Consumer Research, vol.11., pp. 689-693 Provo, UT: Association for Consumer Research.

Atkin, C., Neuendorf, K., \& McDermott, S. (1983) The role of alcohol advertising in excessive and hazardous drinking. Alcohol \& Alcoholism, 23(6), 491-500.

Casswell, S. (2004) Alcohol brands in young people's everyday lives: new developments in marketing, Alcohol and Alcoholism, 6, 471-476.

Casswell, S., \& Zhang, J. F. (1998) Impact of liking for advertising and brand allegiances on drinking and alcohol-related aggression: A longitudinal study. Addiction, 93(8), 1209-1217.

Connolly, G. M., Casswell, S., Zhang, J-F., \& Silva, P. A. (1994) Alcohol in the mass media and drinking by adolescents: A longitudinal study. Addiction, 89, 1255-1263. 
Ellickson, P. L., Collins, R. L., Hambarsoomians, K., \& McCaffrey, D. F. (2005) Does alcohol Advertising promote adolescents drinking? Results from a longitudinal assessment. Addiction, 100(2), 235.

Fillmore, K. (1988) Alcohol use across the life course: A critical review of seventy years of international longitudinal research. Toronto, Canada: Addiction Research Foundation.

Fillmore, K., Hartka, E., Jonstone, B., Leino, E., Motoyoshi, M., \& Temple, M. (1991) A meta-analysis of life course variables in drinking: The Collaborative AlcoholRelated Longitudinal Project. British Journal of Addiction, 86, 1221-1268.

Ford, R., Hawkes, N., \& Elliott, F. (2008) Alarm over the child drinkers with live disease. Times Online, $23^{\text {rd }}$ May. Available at:

www.timesonline.co.uk/tol/news/uk/article3985004

Gill, J. S., Donaghy, M., Guise, J., \& Warner, P. (2007) Descriptors and accounts of alcohol consumption: methodological issues piloted with female undergraduate drinkers in Scotland. Health Education Research, 22(1), 27-36.

Hastings, G., B., Anderson, S., Cooke, E., \& Gordon, R. (2005) Alcohol marketing and young people's drinking: A review of the research. Journal of Public Health Policy, 26, 296-311.

Houghton, E., \& Roche, A. M. (Eds.) (2001) Learning About Drinking. Philadelphia, PA: Brunner-Routledge.

Kohn, P. M., \& Smart, R. G. (1984) The impact of television advertising on alcohol@ An experiment. Journal of Studies on Alcohol, 45(4), 295-301.

Kohn, P. M., \& Smart, R. G. (1987) Wine, women, suspiciousness and advertising. Journal of Studies on Alcohol, 48(2), 161-166.

Lieberman, L. R., \& Orlandi, M. A. (1987) Alcohol advertising and adolescent drinking. Alcohol Health and Research World, 12,(1), 30-43.

Lipsitz, A., Brake, G., Vincent, E. J., \& Winters, M. (1993) Another round for the brewers: Television ads and children's alcohol expectancies. Journal of Applied Social Psychology, 23(6), 439-450.

Matthews, K., Shepherd, J., \& Sivarajasingham, V. (2006) Violence related injury and the price of beer in England and Wales. Applied Economics, 38, 661-670. 
MacRae, F. (2007) Alcohol abuse claims twice as many female lives as 15 years ago. Daily Mail, $22^{\text {nd }}$ October, p. 21.

McCarty, D., \& Ewing, J. A. (1983) Alcohol consumption while viewing alcoholic beverage advertising. International Journal of Addiction, 18, 1011-1018.

McMahon, J., Jones, B., \& O’Donnell, P. (1984) Comparing positive and negative alcohol expectancies in male and female social drinkers. Addiction Research, 1, 349-365.

Nash, A. (2002, August) Children's responses to alcohol advertising on television: A summary of recent research. Report to the Office of Communications, Department of Psychology, University of Hertfordshire, Hatfield, UK.

Richardson, A., \& Budd, T. (2003) Alcohol, Crime and Disorder: A study of young adults. London, UK: Home Office Research Study.

Available at: http://www.homeoffice.gov.uk/rds/pdfs2/hors263.pdf

Robinson, T. N., Chen, H. L., \& Killen, J. D. (1998) Television and music video exposure and risk of adolescent alcohol use. Pediatrics, 10295), e54.

Smart, R. G. (1988) Does alcohol advertising affect overall consumption? A review of empirical studies. Journal of Studies on Alcohol, 49(4), 314-323.

Snyder, L. B., Fleming, M., Slater, M., Sun, H., \& Strizhakova, Y. (2006) Effects of alcohol advertising exposure on drinking among youth. Archives of Pediatrics \& Adolescent Medicine, 160, 18-24.

Sobell, L. C., Sobell, M. B., Riley, D. M., Klajner, F., et al (1986) Effects of television programming and advertising on alcohol consumption in normal drinkers. Journal of Studies on Alcohol, 47(4), 3330340

Sobell, L. C., Sobell, M. B., Toneatto, T., \& Leo, G. I. (1993) Severely dependent alcohol abusers may be vulnerable to alcohol cues in television programs. Journal of Studies on Alcohol, 54(1), 333-340.

Stacy, A., Zogg, J., Unger, J., \& Dent, C. (2004) Exposure to televised alcohol ads and subsequent adolescent alcohol use. American Journal of Health Behaviour, 28(6), 498-509.

Strickland, D. E. (1981, September) The advertising regulation issue: Some empirical evidence concerning advertising exposure and teenage consumption patterns. 
Paper presented at the conference on Control Issues in Alcohol Abuse Prevention, Charleston, South Carolina

Strickland, D. E. (1982) Alcohol advertising: orientation and influence. Journal of Advertising, 1, 307-319.

Strickland, D. E. (1983) Advertising exposure, alcohol consumption and misuse of alcohol. In Grant, Plant \& Williams (Eds) Economics and Alcohol: Consumption and Controls, pp.201-221.

Unger, J., Schuster, D., Zogg, J., Dent, C., \& Stacy, A. (2003) Alcohol advertising exposure and adolescent alcohol use: A comparison of exposure measures, Addiction Research and Theory, 11(3), 177-193.

Wyllie, A., Casswell, S., \& Stewart, J. (1989) The response of New Zealand boys to corporate and sponsorship alcohol advertising on television. British Journal of Addiction, 84(6), 639-646.

Wyllie, A., Millard, M., \& Zhang, J. F. (1996) Drinking in New Zealand: A National Survey 1995. Auckland, NZ: Alcohol \& Public Health Research Unit.

Wyllie, A., Zhang, J. F., \& Casswell, S. (1998) Responses to televised alcohol advertisements associated with drinking behaviour of 10-17 year olds. Addiction, 93, 361-371.

Young, B. M. (2003, March) A review of the literature on the role of advertising in the consumption of alcohol products by younger people. Report to the Office of Communications. School of Psychology, University of Exeter. 